\title{
EL LEGISLADOR EUROPEO Y EL DIPR DE SOCIEDADES EN LA UE*
}

\author{
Rafael ARENAS GARCÍA
}

SUMARIO: 1 INTRODUCCIÓN.-2. DERECHO ORIGINARIO Y DIPR DE SOCIEDADES.2.1. Condicionamientos sustanciales.-2.2. Condicionamientos conflictuales.-3. LA ACTUACIÓN DEL LEGISLADOR EUROPEO.-3.1. Regulación existente.-3.2. Algunas propuestas.-4. CONCLUSIÓN.

\section{INTRODUCCIÓN}

1. No resulta posible entender actualmente el DIPr de sociedades en los Estados miembros de la UE sin considerar la forma en que en él inciden las exigencias derivadas de la libertad de establecimiento de personas jurídicas prevista en el TFUE ${ }^{1}$. Las decisiones dictadas por el Tribunal de Luxemburgo desde la Sentencia Centros de 9 de marzo de $1999^{2}$ han ido definiendo en qué forma esta libertad limita las opciones regulatorias de la actividad internacional de las sociedades de las que disponen los legisladores internos, limitaciones que en algunos casos pueden implicar la imposición de determinadas soluciones, habiéndose convertido, por tanto, el tribunal europeo en un auténtico legislador que con sus pronunciamientos configura el equivalente a un sistema europeo de DIPr de sociedades que desplaza las soluciones nacionales ${ }^{3}$.

* Este trabajo se encuadra en el Proyecto «Desarrollo del derecho de sociedades en la UE: libertad de establecimiento, fiscalidad e interacción con los ordenamientos nacionales», Ministerio de Ciencia e Innovación, referencia DER-2013-46535-P bajo la codirección de los Drs. Carlos Górriz López y Rafael Arenas García. Rafael Arenas es Catedrático de Derecho internacional privado en la Universitat Autónoma de Barcelona.rafael.arenas@uab.es.

${ }^{1}$ Art. 54.1 TFUE: «Las sociedades constituidas de conformidad con la legislación de un Estado miembro y cuya sede social, administración central o centro de actividad principal se encuentre dentro de la Unión quedarán equiparadas, a efectos de aplicación de las disposiciones del presente capítulo a las personas físicas nacionales de los Estados miembros».

2 STJ de 9 de marzo de 1999, Centros Ltd. y Erhvevs-og Selskabsstyrelsen, asunto C-212/97, EU:C: 1999:126.

3 Para un análisis de conjunto de la jurisprudencia del Tribunal de Luxemburgo en la materia me remito a ARENAS GARCÍA, R., «Sombras y luces en la jurisprudencia del Tribunal de Justicia de la UE en materia de Derecho internacional privado de sociedades», en Esplugues Mota, C. y Palao Moreno, G. 
La situación anterior plantea algunos problemas, señaladamente la falta de seguridad jurídica a la que se enfrentan los operadores jurídicos, quienes no pueden conocer a priori cuál será el régimen de las operaciones que emprendan pues la regulación nacional susceptible de aplicación podrá ser matizada como consecuencia de la proyección sobre el caso de la libertad de establecimiento prevista en el Derecho de la UE. A esto, además, se une la incerteza en la determinación del Derecho aplicable a los problemas societarios internacionales.

2. La situación que se acaba de describir explica que se haya planteado en alguna ocasión la necesidad de que el legislador europeo aborde la regulación del DIPr de sociedades. La introducción en el Derecho derivado de normas de conflicto de leyes en materia de DIPr de sociedades podría favorecer la seguridad jurídica ${ }^{4}$ y servir también para encontrar soluciones adecuadas a la cada vez más intensa actividad internacional de las sociedades. No parece, sin embargo, que de momento la UE vaya a abordar esta cuestión. En el Plan de Acción de la Comisión presentado el 12 de diciembre de 2012 no se incluye la regulación del Derecho aplicable a las sociedades ${ }^{5}$.

En este trabajo abordaremos la necesidad y posibilidades de esta actuación legislativa de la UE. Tras un breve examen del estado actual de la materia, incidiendo especialmente en la forma en que la jurisprudencia del Tribunal de Luxemburgo ha configurado el embrión de un sistema implícito de DIPr de sociedades en Europa, entraremos en las materias que deberían ser reguladas (tomando en cuenta para ello los problemas que han sido tratados hasta ahora por los tribunales) y en qué casos debería recurrirse a la técnica conflictual para dicha regulación. Nos ocuparemos aquí solamente de la regulación de las formas societarias nacionales; porque respecto a los diferentes tipos societarios europeos ${ }^{6}$ las dificultades que aquí abordaremos se plantean de una

(eds.), Nuevas fronteras del Derecho de la Unión Europea. Liber amicorum José Luis Iglesias Buhígues, Valencia, Tirant lo Blanch, 2012, pp. 739-759; id., "Lex societatis y derecho de establecimiento», en Arenas García, R., Górriz López, C. y Miquel Rodríguez, J. (coords.), Autonomía de la voluntad y exigencias imperativas en el derecho internacional de sociedades y otras personas jurídicas, Barcelona, Atelier, 2014, pp. 127-169.

4 Véase Sonnenberger, H. J., «État de droit, construction européenne et droit des sociétés», Rev. crit. dr. int. pr., t. 102, 2013, núm. 1, pp. 101-112, esp. p. 112. Véase la propuesta de regulación presentada por el Grupo Europeo de Derecho Internacional Privado (Milán, 16-18 de septiembre de 2016), http://www.gedip-egpil.eu/documents/Milan\%202016/GEDIPs\%20Proposal\%20on\%20Companies.pdf, consultado el 28 de octubre de 2016.

5 http://eur-lex.europa.eu/legal-content/EN/TXT/?qid=1453891145338\&uri=CELEX:52012DC0740, consultado el 28 de octubre de 2016. Véase BenEdeTtelLI, M. V., «Five Lay Commandments for the EU Private International Law of Companies», Yearbook of Private International Law, vol. XVII, 2015/2016, pp. 209-251, esp. pp. 212-213.

6 La Sociedad Anónima Europea (SE), regulada por el Reglamento (CE) núm. 2157/2001, del Consejo, de 8 de octubre, por el que se aprueba el Estatuto de la Sociedad Anónima Europea (SE), DO L núm. 294, de 10 de noviembre de 2001; y por la Directiva 2001/86/CE, del Consejo, de 8 de octubre, por la que se completa el Estatuto de la Sociedad Anónima Europea en lo que respecta a la implicación de los trabajadores (ibid.). Junto a esta la Agrupación Europea de Interés Económico (AEIE), regida por el Reglamento (CEE) núm. 2137/85, del Consejo, de 25 de julio, relativo a la constitución de una agrupación europea de interés económico (AEIE), DO L núm. 199, de 31 de julio de 1985. También la Sociedad Cooperativa Europea (SCE) regida por el Reglamento (CE) núm. 1435/2003, del Consejo, de 
forma diferente. En primer lugar, en relación a estas formas societarias no se dan problemas de reconocimiento, ya que al tratarse de personas jurídicas no sometidas a un Derecho nacional han de ser consideradas como propias desde la perspectiva de todos los Estados miembros de la UE. En segundo término, en relación a las formas societarias europeas no se plantea propiamente un problema de conflicto de leyes, sino de determinación de las fuentes de regulación, entre las que se incluye, por remisión de la normativa europea, el Derecho de origen interno del Estado miembro en el que se fija el domicilio de la persona jurídica ${ }^{7}$. En tercer lugar, porque algunas de las cuestiones que no se encuentran previstas respecto a las sociedades constituidas de acuerdo con lo establecido en el Derecho de origen interno de los Estados miembros de la UE, sí que se encuentran reguladas específicamente en los instrumentos que se ocupan de las formas societarias europeas ${ }^{8}$.

3. Es evidente que hasta ahora las instituciones europeas han mostrado una cierta desconfianza, ya no solamente hacia la norma de conflicto como instrumento adecuado para la regulación societaria, sino incluso hacia el Derecho derivado, sea cual sea la forma que adopte, en materia societaria. Solamente así se explica, por ejemplo, que en un tema tan relevante como es la transferencia internacional del domicilio social aún no hayan concluido los trabajos de elaboración de una Directiva que facilitaría una operación que no es posible impedir, tal como ha establecido el Tribunal de Luxemburgo ${ }^{9}$. No existen razones objetivas para tal desconfianza, pues las normas de conflicto son un buen instrumento para conseguir la seguridad jurídica en un espacio legal complejo como es la UE. En muchos casos será más realista una aproximación a la articulación de los diferentes Derechos europeos mediante técnicas conflictuales que mediante la unificación del Derecho material ${ }^{10}$.

En los siguientes epígrafes intentaremos mostrar de qué forma podrían articularse el Derecho material y el conflictual para dotar de consistencia el

22 de julio, relativo al Estatuto de la sociedad cooperativa europea (SCE), DO L núm. 207, de 18 de agosto de 2003, y por la Directiva 2003/72/CE, del Consejo, de 22 de julio (ibid.).

7 Véanse el art. 9.1.c) del Reglamento de la SE y el art. 8.1.c) del Reglamento de la Sociedad Cooperativa Europea.

8 Señaladamente, la transferencia internacional del domicilio social, véase infra epígrafe 3.1, apartado 17 .

9 Véase LeIBLE, S., «El traslado transfronterizo del domicilio social y la libertad de establecimiento», en Arenas García, R., Górriz López, C. y Miquel Rodríguez, J. (coords.), La internacionalización del Derecho de sociedades, Barcelona, Atelier, 2010, pp. 103-128, esp. pp. 114-120, sobre la jurisprudencia del Tribunal de Luxemburgo relevante para la transferencia internacional del domicilio social, y pp. 123-124, sobre la necesidad de una Directiva en la materia.

10 Véase, por ejemplo, el fracaso del intento de elaboración de una regulación material común para el contrato de compraventa [Propuesta de Reglamento del Parlamento Europeo y el Consejo relativo a una normativa común de compraventa europea, $\operatorname{COM(2011)~} 635$ final, de 11 de octubre de 2011, http:// eur-lex.europa.eu/LexUriServ/LexUriServ.do?uri=COM:2011:0635:FIN:es:PDF, consultada el 28 de octubre de 2016], definitivamente abandonada el 16 de diciembre de 2014, tal como resulta de lo previsto en el Anexo II al Programa de trabajo de la Comisión para el 2015 [COM(2014) 910 final, http://ec.europa. eu/atwork/pdf/cwp_2015_withdrawals_en.pdf, consultado el 28 de octubre de 2016], véase FonTANELLAS Morell, J. M., «La normativa común de compraventa europea ¿punto final o punto y seguido?», AEDIPr, t. XIV-XV, 2014-2015, pp. 447-487, esp. p. 448. 
sistema de DIPr de sociedades que ha comenzado a configurar la jurisprudencia del Tribunal de Luxemburgo, ofreciendo además la necesaria seguridad jurídica a los operadores económicos.

\section{DERECHO ORIGINARIO Y DIPR DE SOCIEDADES}

\subsection{Condicionamientos sustanciales}

4. La jurisprudencia del Tribunal de Luxemburgo ha venido detallando desde el año 1999 en qué forma la libertad de establecimiento condiciona el DIPr de sociedades de los Estados miembros. A través de decisiones que han abordado diferentes aspectos de la actividad internacional de las sociedades han ido fijando ciertas limitaciones imperativas al Derecho interno de los Estados miembros. En principio tales limitaciones deberían reducirse a establecer el límite de la actuación posible del legislador estatal; es decir, qué soluciones serían incompatibles con la libertad de establecimiento, pero sin llegar a imponer concretas regulaciones que se convirtieran en normas que desplazaran a las estatales. Ahora bien, en la práctica algunos de los condicionamientos establecidos por el Tribunal de Luxemburgo tienen tal grado de concreción que realmente podrían ser entendidos como auténticas normas, incluso con cierto grado de detalle, lo que influirá, como veremos, también en el margen del que disponga el legislador europeo en caso de que se decidiera a abordar la regulación del DIPr. Lo que seguirá no pretende ser un comentario de las decisiones existentes ${ }^{11}$, sino la presentación a través de ellas de las exigencias para el DIPr de sociedades que ha identificado el Tribunal de Luxemburgo y a las que debería responder la actuación del legislador europeo.

En este epígrafe trataremos de cómo la jurisprudencia del Tribunal de Luxemburgo afecta a la regulación sustancial de la actividad internacional de las sociedades y en el siguiente examinaremos la incidencia que tiene en la regulación conflictual. Ciertamente las relaciones entre ambas dimensiones son estrechas, pero creemos que es posible establecer esta diferenciación que resulta necesaria para poder considerar el margen que tiene en cada uno de estos ámbitos el Derecho derivado.

5. La primera exigencia que recoge la jurisprudencia del Tribunal de Luxemburgo en relación a la proyección de la libertad de establecimiento sobre el régimen de la actividad internacional de las sociedades es la de la necesidad de inscribir en el registro competente de cada Estado las sucursales en

11 Por lo demás, ya sobradamente realizado, pues los comentarios dedicados a las diferentes decisiones dictadas por el Tribunal de Luxemburgo en materia de Derecho internacional privado de sociedades son inabarcables. Baste comprobar, por ejemplo, el resumen de la doctrina en torno a la Sentencia Centros que se recoge en Garcimartín Alférez, F. J., "La Sentencia Centros del Tribunal de Justicia de las Comunidades Europeas: una visión a través de los comentarios», REEI, 2000, núm. 1. En la nota 3 de dicho trabajo se citan 21 comentarios, solamente a la Sentencia Centros (iy se trata de un trabajo del año 2000, el siguiente al de la publicación de la sentencia!). 
dicho Estado de las sociedades constituidas en otro Estado miembro de la UE. Así se estableció en la primera decisión de la nueva jurisprudencia del Tribunal de Luxemburgo en DIPr de sociedades, la Sentencia Centros de 9 de marzo de $1999^{12}$. Esta obligación de inscripción, sin embargo, no es incompatible con la adopción de medidas tendentes a evitar que la libertad de establecimiento sea utilizada de forma fraudulenta ${ }^{13}$; aunque en la práctica la posibilidad de adoptar tales medidas será reducida, puesto que se hará necesario justificarlas a partir de un fin de interés general, mostrar que son adecuadas y proporcionadas para conseguir el fin pretendido y que no existen medidas alternativas que consigan la protección del interés al que responden las medidas sin limitar la libertad de establecimiento en menor medida que las adoptadas ${ }^{14}$.

La obligación de inscripción presupone en buena lógica la de reconocer la personalidad jurídica de la sociedad; pero no fue hasta la Sentencia Überseering, de 5 de noviembre de $2002^{15}$ cuando se hizo explícita esta obligación de reconocimiento de la personalidad jurídica de las sociedades constituidas de acuerdo con lo previsto en el Derecho de un Estado miembro de la UE.

6. El Tribunal de Luxemburgo también dictaminó que las sociedades constituidas en un Estado miembro podían establecerse en otro Estado miembro sin que resultara admisible exigírseles requisitos específicos en cuanto al capital social y responsabilidad de los administradores más allá de los que había tenido que cumplir en el Estado de constitución de la sociedad ${ }^{16}$. Esta exigencia aparenta tener una dimensión conflictual, ya que parece imponer la aplicación de la ley del Estado de constitución en lo que se refiere al régimen del capital social y de la responsabilidad de los administradores sociales; pero podría contemplarse también desde una perspectiva sustantiva, especialmente en lo que se refiere a la responsabilidad de los administradores, siempre que interpretáramos la decisión no en el sentido de imponer forzosamente la aplicación a la responsabilidad de los administradores la regulación del Estado de origen de la sociedad, sino en el de que tal responsabilidad no puede ser agra-

12 STJ de 9 de marzo de 1999, Centros Ltd y Erhvens-og Selsckabsstyrelsen, asunto C-212/97 (cit. nota 2). En su parte dispositiva establece que los preceptos relevantes del Derecho originario (en el momento en el que se dictó la sentencia los arts. 52 y 58 del Tratado CE, equivalentes actualmente a los arts. 49 y 54 del TFUE) «se oponen a que un Estado miembro deniegue la inscripción de una sucursal de una sociedad constituida de conformidad con la legislación de otro Estado miembro».

13 En la misma Sentencia de 9 de marzo de 1999 se indica en su parte dispositiva que: «No obstante, esta interpretación no excluye que las autoridades del Estado miembro afectado puedan adoptar cualquier medida apropiada para prevenir o sancionar fraudes, ya sea en relación a la propia sociedad [...] ya sea con respecto a los socios con relación a los cuales se haya demostrado que en realidad lo que pretenden, mediante la constitución de una sociedad, es eludir sus obligaciones para con los acreedores privados o públicos establecidos en el territorio del Estado miembro afectado».

14 Véase en este sentido la Sentencia del Tribunal de Luxemburgo de 30 de septiembre de 2003, $\mathrm{Ka}$ mer van Koophandel en Fabrieken voor Amsterdam y Inspire Art Ltd., asunto C-167/01, EU:C:2003:512, apartados 131 a 142 de la sentencia.

15 Sentencia del Tribunal de Luxemburgo de 5 de noviembre de 2002, Überseering BV y Nordic Construction Company Baumanagement GmbH (NCC), asunto C-208/00, EU:C:2002:632.

16 Véase la parte dispositiva de la Sentencia del Tribunal de Luxemburgo de 30 de septiembre de 2003, Inspire Art (cit. supra nota 14). 
vada por normativas específicas del Estado donde la sociedad se encuentra establecida. De esta forma no sería imposible, por ejemplo, que se aplicaran a los administradores medidas menos restrictivas en cuanto a su responsabilidad que las fijadas por el Derecho del Estado de origen de la sociedad.

Esta idea, la de la posibilidad de atenuar las reglas de responsabilidad en beneficio de las sociedades que se encuentran domiciliadas en otro Estado miembro, está presente en la Sentencia de 20 de junio de 2013, Impacto $A z u l^{17}$, donde se mantuvo que no era contrario a la libertad de establecimiento limitar la responsabilidad de las sociedades matrices frente a los acreedores de las filiales cuando tales matrices tuvieran su domicilio social en otro Estado miembro. En este caso no se trataba de determinar qué Derecho debía regir esta responsabilidad de las matrices - se asumía que debía ser el Derecho portugués- sino la posibilidad de que tal Derecho estableciera diferencias entre los supuestos en los que la matriz tuviera su sede en Portugal o en otro Estado miembro de la UE. La respuesta del Tribunal de Luxemburgo es la de que en tanto en cuanto se trate de un trato que beneficie a las sociedades matrices extranjeras frente a las nacionales no hay nada en la regulación europea de la libertad de establecimiento que impida dicha aplicación más beneficiosa ${ }^{18}$.

Podría discutirse la corrección de la decisión, tanto en lo que se refiere a su entendimiento del Derecho portugués ${ }^{19}$ como por la valoración que hace de la forma en que afecta a la libertad de establecimiento de las sociedades la limitación de responsabilidad a favor de las matrices que tienen su sede en un Estado miembro de la UE diferente de Portugal ${ }^{20}$; pero aquí nos interesa

17 Sentencia del Tribunal de Justicia (Sala 9. ${ }^{a}$ ) de 20 de junio de 2013, Impacto Azul Lda. y BPSA 9 -Promoção e Desenvolvimento de Investimentos Imobiliários, S. A., Bouygues Imobiliária- SGPS, Lda, Bouygues Immmobilier, S. A., Aniceto Fernando Viegas, Óscar Cabanez Rodríguez, asunto C-186/12, EU:C:2013:412: «El artículo 49 TFUE debe interpretarse en el sentido de que no se opone a una normativa nacional, como la controvertida en el litigio principal, que excluye de la aplicación del principio de responsabilidad solidaria de las sociedades matrices frente a los acreedores de sus filiales a las sociedades matrices que tengan su domicilio social en el territorio de otro Estado miembro».

18 Se consagra, por tanto, la posibilidad de una discriminación interna en este ámbito, véanse Schмid, J., «Die EuGH-Entscheidung Impacto Azul - Der Impakt der Niederlassungsfreiheit auf das nationale Konzernrecht», GPR, 2014, núm. 1, pp. 40-42, esp. pp. 40-41; TeICHMANN, Ch., «Konzernrecht und Niederlassunsgreiheit. Zugleich Rezension der Entscheidung EuGH, Rs. 186/12 (Impacto Azul)», ZGR, 2014, núm. 1, pp. 45-75, esp. p. 49, y referencias contenidas en nota 15.

${ }_{19}$ Véase Dias R., «Responsabilidad de la matriz por deudas de la filial y Derecho de la UE», en Àrea de Dret Internacional Privat, blog del Área de Derecho Internacional Privado de la UAB, http://blogs.uab. cat/adipr/2013/07/24/responsabilidad-de-la-matriz-por-deudas-de-la-filial-y-derecho-de-la-ue/, consultado el 28 de octubre de 2016.

20 Podría sostenerse que esta limitación de responsabilidad desincentiva la contratación con las filiales en Portugal de sociedades con sede en otros Estados miembros de la UE al no gozar los acreedores de dichas filiales de las ventajas que supone la responsabilidad de la matriz por las deudas de las filiales; aunque, tal como se establece en la propia Sentencia (apdo. 37) esta responsabilidad puede establecerse por vía contractual (véase ScHMIDT, J., op. cit., nota 18, p. 41). Ahora bien, esta posibilidad no supondría la aplicación completa del régimen de grupos, que prevé no solamente desventajas para la sociedad matriz (la responsabilidad por las deudas de la filial) sino también ventajas, como puede ser la posibilidad de recibir transferencias desde la sociedad dominada. Véanse sobre esta perspectiva, Teichmann, Ch., op. cit., nota 18, pp. 68-69; Conac, P.-H., «Droit européen des sociétés. Une législation 
detenernos en la interpretación que hace el tribunal de la relación entre el Derecho material de sociedades, en este caso en relación a la responsabilidad de las matrices por las deudas de sus filiales, y el derecho a la libertad de establecimiento previsto en el Derecho originario de la UE. De la sentencia se deriva de manera directa que es compatible con dicha libertad minorar la responsabilidad de las matrices con sede en otro Estado miembro respecto a la de las matrices que han sido constituidas en el Estado en el que se plantea la determinación de la responsabilidad. De manera indirecta se desprende que sería contrario a dicha libertad de establecimiento agravar la responsabilidad de las matrices extranjeras frente a las nacionales; siempre, por supuesto, que estas extranjeras sean sociedades constituidas en un Estado miembro ${ }^{21}$.

7. De la jurisprudencia del Tribunal de Luxemburgo también se desprende que cada Estado miembro ha de permitir que las sociedades constituidas de acuerdo con su Derecho se transformen en sociedades regidas por el Derecho de otro Estado miembro. Inicialmente esta manifestación del derecho a la libertad de establecimiento fue afirmada como obiter dicta en la Sentencia del Tribunal de Luxemburgo de 16 de diciembre de 2008 (Cartesio) ${ }^{22}$ y confirmada en la Sentencia VALE, de 12 de julio de $2012^{23}$ donde, además, se añadió que el Estado de destino de la sociedad emigrada no podía excluir a las sociedades extranjeras que deseaban transformarse en sociedades nacionales de las previsiones establecidas para la transformación de sociedades nacionales y, en concreto, no podían limitar la posibilidad de que la sociedad extranjera fuera considerada predecesora legal de la sociedad transformada. Además deberían tenerse en cuenta los documentos procedentes de las autoridades del Estado de origen de la sociedad ${ }^{24}$.

Resulta curioso o, al menos, destacable, que mientras el Tribunal de Luxemburgo prevé que han de establecerse mecanismos que permitan la transformación de una sociedad regida por el Derecho de un Estado miembro de la UE en una sociedad regida por el Derecho de otro Estado miembro, se mantenga que sea compatible con la libertad de establecimiento que regula el Derecho europeo la imposibilidad de que una sociedad fije su domicilio social en un Estado miembro diferente del de su constitución ${ }^{25}$.

d'un État membre sur les groupes qui discrimine les sociétés nationales n'est pas contraire à la liberté d'établissement», Revue des sociétés, 2014, núm. 3, pp. 179-185, esp. p. 184.

21 Las sociedades constituidas en Estados terceros en ningún caso se benefician de la libertad de establecimiento, véase la Sentencia del Tribunal de Justicia (Sala 1. ${ }^{\text {a }}$ ) de 11 de septiembre de 2014, Kronos International Inc. y Finanzamt Leverkusen, asunto C-47/12, EU:C:2014:2200.

22 Sentencia del Tribunal de Justicia (Gran Sala) de 16 de diciembre de 2008, CARTESIO Oktató es Szolgáltató bt, asunto C-210/06, EU:C:2008:723.

${ }_{23}$ Sentencia del Tribunal de Justicia (Sala 3. ${ }^{a}$ ) de 12 de julio de 2012, VALE ÉpítésiKft, asunto C-378/10, EU:C:2012:440. Véase el análisis de esta sentencia de GARCIMARTín ALFÉrEZ, F. J., «El cambio de la lex societatis: una forma especial de transformación societaria. Comentario a la sentencia del TJUE (as. Vale Épitésikft)», La Ley, 2012, núm. 7992, de 28 de diciembre de 2012 (también publicado en Deloitte, enero de 2013, http://www.ciss.es/publico/deloitte/2013_71_A_039.pdf, consultado el 28 de octubre de 2016, pp. 39-46).

24 Véase la parte dispositiva de la sentencia.

25 Véase la parte dispositiva de la Sentencia Cartesio ya mencionada (supra nota 22). 
8. Más allá del Derecho privado, también se ha planteado la forma en que la libertad de establecimiento afecta a la capacidad impositiva de los Estados miembros de la UE. En la Sentencia National Grid, de 29 de noviembre de $2011^{26}$ el Tribunal indicó que no era compatible con la libertad de establecimiento un régimen impositivo que supusiera una limitación inadecuada a la movilidad societaria. Esto se traducía en la necesidad de adecuar el régimen de los impuestos de salida (el impuesto de sociedades que había de satisfacerse en el caso de transferencia internacional del domicilio social sobre las plusvalías latentes de la sociedad) a las exigencias europeas ${ }^{27}$. Esta sentencia precedió a varias en relación a los impuestos de salida que obligaron a modificar la normativa de varios países europeos en la materia ${ }^{28}$.

9. Así pues, de acuerdo con la jurisprudencia hasta ahora dictada por el Tribunal de Luxemburgo resulta que la libertad de establecimiento reconocida por el Derecho europeo originario obliga a reconocer la personalidad jurídica de todas las sociedades constituidas de acuerdo con el Derecho de otros Estados miembros, a facilitar la inscripción de sus sucursales allí donde se hayan instalado y a no establecer normas más rigurosas que las del Estado de origen en cuanto a responsabilidad de la sociedad o de sus administradores. Además ha de permitirse la transformación de las sociedades nacionales en sociedades regidas por el Derecho de otro Estado miembro. También han de evitarse las medidas tributarias que dificulten la transferencia internacional del domicilio social, estando tan solo permitidas aquellas que sean necesarias para la consecución de un fin de interés general, sean adecuadas para dicho fin, no discriminatorias, proporcionales y, además, imprescindibles por no existir medidas alternativas que consigan proteger de igual manera el fin de interés general con una lesión menor de la libertad de establecimiento.

Es claro que el catálogo anterior no agota las consecuencias de la proyección sobre el Derecho de sociedades de las exigencias derivadas de la libertad de establecimiento. El Tribunal de Luxemburgo tan solo se ha pronunciado sobre aquellas cuestiones que han resultado litigiosas en la práctica; pero sin que se descarte que existan otras manifestaciones de la incidencia de la libertad de establecimiento en el Derecho societario. De hecho, y tomando en cuenta la jurisprudencia existente hasta el momento, podemos afirmar que todos los Estados están obligados, por una parte, a reconocer la personalidad jurídica de las sociedades constituidas en otros Estados miembros, a admitir la presencia en su territorio de establecimientos de dichas sociedades y a no

26 STJ (Gran Sala) de 29 de noviembre de 2011, National Grid Indus BV e Inspecteur van de Belastingsienst Rijnmond/kantoor Rotterdam, asunto C-371/10, EU:C:2011:785.

27 Me remito a ARENAS GARcía, R., «Transferencia intraeuropea de la sede de dirección de la empresa: Derecho privado, fiscalidad y libertad de establecimiento [Comentario a la STJUE (Gran Sala) de 29 de noviembre de 2011, asunto C-371/10, National Grid Indus BV e Inspecteur van de Belastingsdienst Rijnmond/kantoor Rotterdam]», Diario La Ley, 30 de abril de 2012, núm. 7848, pp. 1-7.

${ }_{28}$ Véase ZHANG, H., "La compatibilidad de los impuestos de salida y la libertad de establecimiento desde la perspectiva española», en Arenas García, R., GóRriz López, C. y Miquel Rodríguez, J. (coords.), op. cit., nota 3, pp. 191-208. 
aplicarles ninguna medida que suponga una carga para la sociedad superior a la que se derivaría de la aplicación del Derecho del Estado de constitución de la sociedad ${ }^{29}$. De la aplicación de dicho Derecho en materia de DIPr de sociedades nos ocuparemos en el siguiente epígrafe, pero aquí es necesario destacar que este Derecho del Estado de constitución constituye un límite que el Derecho del Estado del establecimiento no puede traspasar salvo en el caso de que exista un fin de interés general que haya de ser alcanzado y no exista alternativa para ello que no sea la imposición de una medida que suponga algún tipo de gravamen sobre la sociedad.

La segunda consecuencia de dicha proyección de la libertad de establecimiento sobre el Derecho societario es la necesidad de que los Estados europeos permitan que las sociedades constituidas de acuerdo con su propio Derecho se transformen en sociedades regidas por el Derecho de otros Estados miembros. Además, no pueden limitar la movilidad de las sociedades mediante medidas impositivas que desincentiven el traslado de la sede de una sociedad europea de un Estado miembro de la UE a otro Estado miembro. A salvo de que dicha medida pueda justificarse de acuerdo con lo indicado en los párrafos anteriores.

\subsection{Condicionamientos conflictuales}

10. La incidencia de la libertad de establecimiento sobre la regulación de la actividad internacional de las sociedades no se limita a las consideraciones sustanciales que hemos examinado someramente en el epígrafe anterior, sino que se extiende también a ciertos condicionamientos conflictuales, tal como veremos a continuación. Antes de entrar en ello, sin embargo, conviene aclarar que aquí no consideraremos como un condicionamiento conflictual la obligación de reconocimiento de la personalidad jurídica de todas las sociedades constituidas según lo previsto en el Derecho de un Estado miembro de la UE, con independencia de que en dicho Estado se ubique (o no) la sede real de la sociedad.

29 No se descarta que en el futuro puedan plantearse ante el Tribunal de Luxemburgo nuevos supuestos de limitación de la libertad de establecimiento que deberían ser contrastados con las exigencias de dicha libertad. Así, por ejemplo, en Alemania se ha denegado la inscripción de una sucursal de una sociedad inglesa por constar como directivo de la sociedad una persona que había sido descalificada como directivo en Alemania y que, presumiblemente, habría pretendido eludir la prohibición de ejercer como tal mediante la constitución de una sociedad inglesa (véase Sentencia del Bundesgerichtshof de 7 de mayo de 2007, II ZB 7/06, http://lexetius.com/2007,1419, consultada el 28 de octubre de 2016. Véase RINGE, W.-G., "Corporate Mobility in the European Union -a Flash in the Pan? An empirical study on the success of lawmaking and regulatory competition", ECFR, vol. 10, 2013, núm. 2, pp. 230-267, esp. p. 259, nota 104). El Tribunal alemán entendió que esta limitación no suponía una vulneración de la libertad de establecimiento; pero no es posible saber lo que interpretaría el Tribunal de Luxemburgo en caso de tener que conocer de un supuesto como este. Sobre la forma en que las exigencias de la libertad de establecimiento limita los Derechos de los Estados miembros véase Grundmann, S., European Company Law. Organization, Finance and Capital Markets, 2. ${ }^{\text {a }}$ ed., Cambridge-Amberes-Portland, Intersentia, 2012, pp. 138-139. 
Es cierto que según ciertas concepciones del DIPr de sociedades la regulación del reconocimiento de sociedades extranjeras es inescindible de la determinación de la ley rectora de la sociedad (lex societatis) ${ }^{30}$; pero esta aproximación debería ser matizada ya que no existe problema en reconocer la personalidad jurídica de una sociedad y, asumiendo dicho reconocimiento, aplicar a determinadas cuestiones de su estatuto un Derecho diferente al de constitución ${ }^{31}$. Es por eso por lo que hemos considerado la obligación de reconocimiento de la personalidad jurídica de todas las sociedades constituidas en los Estados miembros de la UE como una consecuencia sustancial de la libertad de establecimiento, y no conflictual.

11. Más allá de esta obligación de reconocimiento existen algunos condicionamientos estrictamente conflictuales que se derivan de la jurisprudencia del Tribunal de Luxemburgo. En concreto, se ha planteado la necesidad de considerar el Derecho del Estado de constitución de la sociedad en lo que se refiere a la regulación de la capacidad de la sociedad y la responsabilidad de los administradores sociales.

La primera proyección clara de la libertad de establecimiento sobre la regulación conflictual de las sociedades fue explicitada en la Sentencia del Tribunal de Luxemburgo en el caso Überseering, del año $2002^{32}$. En ella se estableció que la capacidad de una sociedad constituida en un Estado miembro debía regirse en otros Estados miembros por el Derecho del Estado de constitución de la sociedad. Se apartó así la Sentencia de las Conclusiones del Abogado General que, con mejor criterio, defendían que no existiera pronunciamiento del tribunal sobre el Derecho rector de la capacidad de la sociedad por considerar que se trataba de una cuestión de mera legalidad interna que no estaba afectada por la libertad de establecimiento ${ }^{33}$. Ahora bien, más allá de la crítica que pueda realizarse a la sentencia, lo cierto es que el principio quedó establecido y, además, fue también reiterado casi inmediatamente en la Sentencia Inspire Art del año $2003^{34}$.

12. De acuerdo, por tanto, con la jurisprudencia del Tribunal de Luxemburgo es necesario aplicar el Derecho del Estado de constitución de la sociedad en lo que se refiere a la regulación de la capacidad de la sociedad y ese Derecho ha de ser al menos tenido en cuenta en la determinación del régimen de la responsabilidad de los administradores. No es claro que tal Derecho haya de ser necesariamente aplicado, pudiendo, quizás ser desplazado por otro cuando esto no implique colocar a los administradores de la sociedad en una situación peor que la que resulta del Derecho del Estado de constitu-

30 Véase Calvo Caravaca, A.-L., "Artículo 9, apartado 11», en Albaladejo, M. y Díaz Alabart, S. (dirs), Comentarios al Código Civil y a las Compilaciones Forales, Madrid, EDERSA, t. I, vol. II (2. ${ }^{\mathrm{a}}$ ed.), 1995, pp. 479-525, esp. p. 513.

31 Véase GrundmanN, S., op. cit., nota 29, p. 128 y referencias allí contenidas.

32 Véase supra nota 15.

33 Véase Arenas García, R., «Sombras y luces...», op. cit., nota 3, pp. 749-750.

34 Véase supra nota 14. 
ción ${ }^{35}$. Tal como se ha adelantado, la jurisprudencia sentada en la Sentencia Impacto Azul apoyaría esta posibilidad.

De acuerdo con lo anterior, por tanto, resultaría que el Derecho originario de la UE en materia de libertad de establecimiento haría necesario considerar el Derecho del Estado de constitución de la sociedad en diversas circunstancias y con distinto grado de intensidad. Mientras en lo que se refiere a la capacidad de la sociedad la aplicación de dicho Derecho de constitución sería imperativa en otros supuestos tan solo sería necesaria la toma en consideración del mismo. Así sucedería en el caso de la responsabilidad de los administradores sociales y también, como veremos inmediatamente, en los casos de transformación de una sociedad regida por el Derecho de un Estado miembro en una sociedad regida por el Derecho de otro Estado miembro.

13. Tal como se había adelantado, el Tribunal de Luxemburgo indicó mediante un obiter dicta en la Sentencia Cartesio $^{36}$ que no resultaría compatible con el Derecho de la UE la legislación de un Estado miembro que no permitiera la transformación de una sociedad regida por el Derecho de dicho Estado en una sociedad sometida al Derecho de Estado miembro; ahora bien, añadía que tal obligación de facilitación existiría si el Derecho al que pretendía someterse la sociedad permitía tal transformación ${ }^{37}$. Esta llamada al Derecho del Estado al que desea trasladarse la sociedad es coherente con el principio según el cual ha de considerarse el Derecho del Estado de constitución de la sociedad, ya que en el supuesto del transformación de la sociedad en una regida por el Derecho de otro Estado, el Derecho de este último país asume el papel de Estado de constitución en lo que se refiere a la nueva forma adoptada por la sociedad.

Ciertamente, el Derecho del Estado de constitución - tanto el Estado de constitución originaria de la sociedad como aquel al que pretenda trasladarse la misma - no dispone de carta blanca según el Derecho de la UE en cuanto a la regulación societaria. Así, en el apartado anterior hemos visto cómo tal Derecho ha de facilitar en determinados supuestos la inmigración societaria $^{38}$ y no puede regular la fiscalidad de las operaciones societarias de manera tal que injustificadamente limita o desincentive la movilidad societaria ${ }^{39}$. Además, y tal como se acaba de recordar, tampoco puede impedir la transformación de las sociedades regidas por su Derecho en sociedades regidas por el Derecho de otro Estado miembro. De esta forma, se relacionan tanto las exigencias conflictuales como las materiales. Mientras las materiales implican un determinado contenido sustancial en la regulación del Derecho de los Estados, las conflictuales se concretan en la necesaria consideración del Derecho del Estado rector de la sociedad, entendido este como el de la cons-

\footnotetext{
35 Véase Arenas García, R., "Lex societatis y derecho de establecimiento», op. cit., nota 3, pp. 152154.

36 Véase supra nota 22.

37 Véanse apartados 111-113 de la Sentencia Cartesio.

38 Véase supra párr. 7.

39 Sentencia National Grid, véase supra nota 26.
} 
titución de la sociedad o el del nuevo Derecho al que se somete esta en los casos de transformación societaria. Ahora bien, esta consideración no implica necesariamente aplicación de tal Derecho.

14. La justificación de esta toma en consideración del Derecho según el cual se ha constituido la sociedad o del Derecho que la regirá tras su transformación en un tipo societario propio de un Estado miembro de la UE diferente del Estado de constitución no está seguramente suficientemente explicitada y justificada en la jurisprudencia del Tribunal de Luxemburgo. Por una parte, podría no resultar del todo claro que del Derecho originario en materia de libertad de establecimiento se derive el derecho a la transformación societaria ${ }^{40}$. Por otra parte, hubiera sido posible sostener que el reconocimiento de la personalidad jurídica de las sociedades constituidas según lo previsto en el Derecho de un Estado miembro no exigía necesariamente la aplicación de dicho Derecho para la regulación de tal capacidad ${ }^{41}$. Finalmente, en lo que se refiere a la responsabilidad de los administradores sociales, existen razones que justificarían la consideración no del Derecho del Estado de constitución de la sociedad, sino del país en el que el administrador desarrolla su actividad.

Ahora bien, pese a lo anterior, no se trata aquí tanto de criticar la jurisprudencia del Tribunal de Luxemburgo en la materia como de constatar que, efectivamente, existe un cierto condicionamiento de las soluciones conflictuales en materia de DIPr de sociedades como consecuencia de la proyección de las exigencias derivadas de la libertad de establecimiento sobre la actividad internacional de las sociedades. Este condicionamiento, que va siendo desvelado por la jurisprudencia del Tribunal de Justicia de la UE a raíz de los diferentes casos que le son presentados, no se encuentra recogido en ninguna norma que de forma explícita y completa determine el régimen conflictual de las sociedades en la UE. Esta indeterminación, unida a la que también afecta a la regulación material de la actividad internacional de las sociedades, justificaría probablemente una actuación del legislador europeo, lo que no ha sido abordado más que parcialmente y tan solo en lo que se refiere a la regulación

40 La mayoría de los autores, sin embargo, defienden que del derecho a la libertad de establecimiento se deriva la posibilidad de transformación societaria. Véase, por ejemplo, en España, GARCIMARTín ALFÉREZ, F. J., op. cit., nota 23, pp. 44-45, entre otros comentaristas de la jurisprudencia del Tribunal de Luxemburgo. La base que en ocasiones se utiliza para llegar a esta conclusión es la consideración de que, al igual que previamente en la Sentencia SEVIC [STJ (Gran Sala) de 13 de diciembre de 2005, asunto C-411/03, SEVIC Systems AG, EU:C:2005:762], el Tribunal se limita a establecer que no puede excluirse a las sociedades extranjeras de las transformaciones de sociedades regidas por el propio Derecho (en la Sentencia SEVIC se aplicó este mismo principio en relación a las fusiones de sociedades). Podría plantearse, sin embargo, que no hay posible equivalencia entre los supuestos internos de transformación societaria y los internacionales. La conversión de una sociedad regida por un Derecho en otra regida por un Derecho diferente es radicalmente distinta de cualquier otra transformación societaria que no implica el cambio de ley rectora de la sociedad. De ahí que la equivalencia pretendida pudiera ser cuestionable. Para una referencia a la doctrina crítica con este planteamiento Véase GRUNDMANN, S., op. cit., nota 29, p. 617, nota 130.

41 Véanse las Conclusiones del Abogado General Ruiz-Jarabo Colomer en el caso Überseering, presentadas el 4 de diciembre de 2001, esp. apartados 63 a 69. 
sustancial. En el siguiente epígrafe consideraremos la tarea que hasta ahora ha realizado el legislador europeo y aventuraremos en qué forma podría avanzarse en esa regulación de la actividad internacional de la sociedades en Europa.

\section{LA ACTUACIÓN DEL LEGISLADOR EUROPEO}

\subsection{Regulación existente}

15. Tal como se ha adelantado, la actividad internacional de las sociedades en Europa se encuentra solo parcialmente regulada por el Derecho derivado europeo. Diversas directivas han abordado algunas de los aspectos de esta materia, pero han dejado algunas cuestiones completamente huérfanas de normativa; así, la transferencia internacional de la sede social. Esta regulación, además, ha optado por una aproximación material, de tal forma que prácticamente no existen normas que aborden, ni siquiera tangencialmente las cuestiones conflictuales. No hay, por tanto, Derecho derivado que resuelva las incógnitas que, como hemos visto, aún deja abiertas la jurisprudencia del Tribunal de Luxemburgo en la materia.

16. De los diferentes supuestos de actividad internacional de las sociedades, el que tiene una regulación más detallada es la fusión internacional de sociedades. La Directiva 2005/56/CE sobre fusiones transfronterizas trata esta cuestión con detalle ${ }^{42}$. Junto a la Undécima Directiva sobre publicidad de sucursales ${ }^{43}$ son las únicas normas de Derecho derivado que se ocupan de manera directa de la regulación de la actividad internacional de las sociedades dentro del Mercado Europeo. Más allá de los límites del Derecho privado, sin embargo, hemos de considerar también la Directiva 2011/96/UE sobre régimen fiscal común para matrices y filiales de Estados miembros diferentes ${ }^{44}$. Una regulación en su conjunto insuficiente para la problemática que resulta de una actividad extraterritorial de las sociedades extraordinariamente intensa, sobre todo a partir de los primeros años del siglo XXI.

De lo limitado de este Derecho derivado da cuenta el que una operación tan trascendente como es la transferencia internacional del domicilio social no haya dado lugar a ninguna norma, habiéndose paralizado hace tiempo los

42 Directiva 2005/56/CE, del Parlamento Europeo y del Consejo, de 26 de octubre, relativa a las fusiones transfronterizas de las sociedades de capital, DO L núm. 310, de 25 de noviembre de 2005. Este detalle no ha impedido, sin embargo, que algunas cuestiones relativas a las fusiones transfronterizas hayan resultado problemáticas; véase, por ejemplo, la STJ (Sala 3. ${ }^{\text {) }}$ ) de 7 de abril de 2016, asunto C-483/14, KA Finanz AB y Sparkassen Versicherung AB Vienna Insurance Group, EU:C:2016:205.

43 Undécima Directiva 89/666/CEE, del Consejo, de 21 de diciembre, relativa a la publicidad de las sucursales constituidas en un Estado miembro por determinadas formas de sociedades sometidas al Derecho de otro Estado, DO L núm. 395, de 30 de diciembre de 1989.

44 Directiva 2011/96/UE, del Consejo, de 30 de noviembre, relativa al régimen fiscal común aplicable a las sociedades matrices y filiales de Estados miembros diferentes, DO L núm. 345, de 29 de diciembre de 2011. 
trabajos relativos a una Decimocuarta Directiva sobre el traslado internacional del domicilio social ${ }^{45}$ y también que no exista ninguna regulación de las cuestiones conflictuales vinculadas a las operaciones societarias internacionales, a salvo de las remisiones que se hacen a la legislación interna de los Estados miembros en el marco de la regulación sustancial de las operaciones de fusión transfronteriza o de la publicidad de las sucursales ${ }^{46}$.

17. Existen varios motivos que explican esta ausencia de regulación. Algunos son específicos para algunos instrumentos concretos (por ejemplo, la Decimocuarta Directiva en materia de transferencia internacional del domicilio social), pero otros tienen carácter general. Entre ellos uno ha de ser especialmente considerado. Es el relativo a la relación existente entre las formas societarias nacionales y europeas.

Como es sabido, junto a las formas societarias reguladas por el Derecho de origen interno de los Estados miembros existen formas societarias europeas $^{47}$. Estas formas societarias fueron creadas, precisamente, para facilitar las operaciones societarias internacionales (fusión de sociedades regidas por Derechos diferentes, transferencia internacional del domicilio social, establecimiento de sociedades en Estados diferentes del de constitución). La dicción de los considerandos del Reglamento sobre la SE es clara al respecto ${ }^{48}$. Se trataba de ofrecer un instrumento a los operadores jurídicos o económicos que facilitara las operaciones de reestructuración internacional de las sociedades y, en general, su actividad extraterritorial para superar las dificultades derivadas de la utilización de las formas nacionales.

45 Véanse LeIBLE,S., op. cit., nota 9, pp. 123-124; KIENINGER, E.-M., «Verwaltungssitzverlegung», en LeIBle, S. y ReIchert, J. (eds.), Internationales Gesellschaftsrecht. Grenzüberschreitende Unwandlungen, vol. 6 de Münchener Handbuch des Gesellschaftsrechts, Múnich, C. H. Beck, 2013, pp. 1159-1178, esp. p. 1176; Hansen, J. L., "The Vale Decision and the Courts' Case La won the Nationality of Companies», ECFR, vol. 10, 2013, núm. 1, pp. 1-17, esp. pp. 15-16; HÜBNER, L., «Der grenzüberschreitende Formwechsel nach Vale - zur Satzungssitzverlegung von Luxemburg nach Deutschland», IPRax, 2015, núm. 2, pp. 134-139, esp. p. 139.

46 Así, por ejemplo, el art. 3.1 de la Directiva sobre fusiones transfronterizas se remite a la regulación del Estado de las sociedades que participan en la fusión para la concreción de las operaciones cubiertas (art. 3.1) o para la determinación de las sociedades que pueden participar en la operación (art. 4.1). En la Undécima Directiva, sobre publicidad de sucursales, se establece, por ejemplo, que la publicidad de la sucursal deberá realizarse según lo previsto en el Estado en que radique la sucursal (art. 1.1). El art. 3 de la misma Directiva (entre otros) también incluye remisiones a lo previsto en el Derecho de origen interno de los Estados miembros; en este caso al del Estado miembro al que está sometida la sociedad.

47 Véase supra nota 6.

48 Cdo. 3, por ejemplo: «La realización de operaciones de reestructuración y de cooperación en las que intervienen empresas de distintos Estados miembros tropieza con dificultades de orden jurídico, fiscal y psicológico. Las medidas de aproximación del Derecho de sociedades de los Estados miembros, canalizadas a través de Directivas basadas en el artículo 44 del Tratado, pueden solucionar algunas de esas dificultades. Sin embargo, dichas medidas no dispensan a las empresas sometidas a ordenamientos jurídicos diferentes de la obligación de escoger una forma de sociedad regulada por un ordenamiento jurídico nacional determinado». Y continúa en el 6: «Resulta esencial establecer, tanto como sea posible, una correspondencia entre la unidad económica y la unidad jurídica de la empresa en la Comunidad. A tal fin, es conveniente prever la constitución, junto a las sociedades de Derecho nacional, de sociedades cuya formación y funcionamiento estén regulados por un Reglamento de Derecho comunitario, directamente aplicable en todos los Estados miembros». 
18. Lo cierto, sin embargo, es que las dificultades que pretendían resolver las formas societarias europeas desaparecieron en gran medida gracias a la jurisprudencia del Tribunal de Luxemburgo iniciada con la Sentencia Centros y a la que nos hemos referido de forma sumaria en el epígrafe 2 de este trabajo. Esta jurisprudencia aparece justamente en el momento en el que concluyen los trabajos relativos a la SE y que se habían desarrollado en un momento en el que, efectivamente, eran grandes las limitaciones para la eficacia de las formas societarias nacionales como instrumentos de reestructuración empresarial internacional. La falta de obligado reconocimiento en un Estado miembro de las formas societarias creadas en otro Estado miembro implicaba una dificultad enorme que no podría, seguramente, ser salvada mediante la actuación del legislador europeo. Es por esto que dicho legislador había optado por enfocar este problema de reestructuración societaria internacional a través de otro mecanismo, las formas societarias europeas.

Sin embargo, justamente en el momento en el que aparecen estas formas societarias europeas, las dificultades que planteaba la utilización de las formas societarias nacionales desaparece o al menos disminuyen como consecuencia de la obligación de que en todos los Estados miembros se reconozca la personalidad jurídica de las sociedades constituidas según lo establecido en el Derecho de otros Estados miembros. A partir de ese momento se abre una cierta competencia entre las formas societarias europeas y las formas societarias nacionales como vehículos apropiados para articular la actividad internacional de las sociedades dentro del Mercado Europeo. En esta competición no caben excesivas dudas de que el triunfo ha sido, de momento, para las formas societarias nacionales, de tal forma que se ha incrementado tanto la constitución de sociedades en un Estado miembro para operar en otros Estados miembros a través de sucursales como las fusiones internacionales de sociedades regidas por diferentes Derechos ${ }^{49}$.

En este contexto, sin embargo, la ausencia de una regulación europea de la transferencia internacional del domicilio social supone una dificultad de consideración para este tipo de operaciones. Pese a que, como hemos visto, el Tribunal de Luxemburgo ha establecido la falta de compatibilidad con el principio de libertad de establecimiento la prohibición de que las sociedades propias se transformen en sociedades regidas por el Derecho de otro Estado

49 Sobre el incremento de la constitución de sociedades en el Reino Unido con el fin de operar en una pluralidad de Estados europeos, véase GELTER, M., "Centros, the Freedom of Establishment for Companies, and the Court's Accidental Vision for Corporate Law», European Corporate Governance Institute, Law Working Paper, núm. 287/2015, http://ssrn.com/abstract=2564765, consultado el 28 de octubre de 2016, p. 22. En general, sobre la forma en que la jurisprudencia del Tribunal de Luxemburgo en materia de libertad de establecimiento de sociedades ha influido en la práctica y en la legislación de los Estados miembros véase Ringe, W.-G., op. cit., nota 29, passim. En este estudio, sin embargo, ya se advierte que tras el inicial aumento de la utilización de formas societarias inglesas para operar en el conjunto de Europa había comenzado a disminuir el recurso a las sociedades británicas, incluso antes de que los legisladores de otros países europeos hubiesen comenzado a modificar sus Derechos internos a fin de evitar que sus operadores económicos recurrieran a formas societarias extranjeras (véase p. 257). 
miembro, la ausencia de una regulación precisa de la forma en que ha de realizarse esa transformación limita la eficacia del principio establecido por el Tribunal de Luxemburgo.

19. Así pues, la regulación que actualmente contiene el Derecho derivado en materia de actividad internacional de las sociedades nacionales dentro de la UE se limita a la publicidad de las sucursales en un Estado miembro de sociedades regidas por el Derecho de otro Estado miembro y la fusión de sociedades regidas por Derechos de diferentes Estados europeos. Ni la determinación del Derecho rector de la sociedad (la lex societatis) ni la concreción de su contenido ni, finalmente, el régimen de la transferencia internacional de la sede social - tanto para aquellos casos en los que la transferencia implica cambio de la ley rectora de la sociedad como aquellos otros en los que el traslado del domicilio no altera el Derecho al que se encuentra sometida la sociedad - ha sido objeto de atención por parte del legislador europeo.

En el siguiente epígrafe se realizarán algunas propuestas de regulación de la actividad internacional de las sociedades. Tal como intentaremos mostrar se trata de normativas que facilitarían esta actividad internacional, en algún caso las modificaciones estructurales que podrían convenir a las sociedades europeas y que, sobre todo paliarían la inseguridad jurídica que ahora se vive como consecuencia de una situación en la que la auténtica regulación es la que resulta de la articulación de una serie de decisiones que, resolviendo sobre casos concretos, es imposible que se configuren como un sistema completo de DIPr de sociedades en Europa.

\subsection{Algunas propuestas}

20. De acuerdo con lo que se ha expuesto hasta ahora resulta conveniente una regulación europea de ciertas cuestiones vinculadas a la actividad internacional de las sociedades en aquellos casos en los que dicha actividad resulta relevante para la libertad de establecimiento en la UE. A continuación se presentarán algunas propuestas normativas que podrían facilitar esa actividad societaria internacional.

En estas propuestas se intentará diferenciar entre lo que resulta obligado por las exigencias derivadas de la libertad de establecimiento y aquellas cuestiones en las que el legislador dispondría de varias posibilidades de regulación. Este acercamiento aleja lo que aquí se plantea de otros trabajos en los que esta distinción no ha sido considerada como un eje esencial; así, por ejemplo, en la propuesta que realiza el GEDIP, tal como tendremos ocasión de concretar en los siguientes apartados.

21. Según lo que se ha visto hasta ahora, el Tribunal de Luxemburgo ha concluido que, al menos en algunos casos, la libertad de establecimiento que regula el Derecho de la UE exige que determinadas cuestiones societarias 
sean regidas por el Derecho del Estado de constitución de la sociedad ${ }^{50}$. A partir de aquí, la formulación de una norma que prevea que el Derecho rector de la sociedad, su lex societatis es la del Estado en el que la sociedad se ha constituido daría cumplimiento a lo establecido en la jurisprudencia del Tribunal de Justicia y mejoraría la seguridad jurídica dentro de la UE ${ }^{51}$.

Esta norma, sin embargo, aún debería abordar algunas cuestiones que la jurisprudencia del Tribunal de Luxemburgo no ha resuelto, además de articularse son las soluciones que pueden darse a los supuestos en los que no opera la libertad de establecimiento regulada por el Derecho europeo ${ }^{52}$.

En lo que se refiere a los supuestos no afectados por la libertad de establecimiento, resultaría que una actuación de la UE no podría basarse en la competencia europea en materia societaria, limitada precisamente a los supuestos sobre los que se proyecta la libertad de establecimiento; esto es, aquellos en los que la sociedad está regida por el Derecho de un Estado miembro de la $\mathrm{UE}^{53}$. Ahora bien, aun así la competencia reguladora podría resultar de la que se le atribuye a la UE para hacer compatibles la regulación en materia de conflictos de leyes ${ }^{54}$.

Tal como se ha indicado, el Derecho rector de la sociedad, según la jurisprudencia del Tribunal de Luxemburgo, es el del Estado de constitución de la sociedad, entendido como aquel Derecho según el cual la sociedad ha sido creada. Ahora bien, hemos de tener en cuenta que en aquellos casos en los que se haya producido la transferencia de sede social con cambio de la lex

50 Vid. supra párr. 11.

51 Sobre la conveniencia de esta regulación para mejorar la seguridad jurídica véase BoRG-BARTHET, J., The Governing Law of Companies in EU Law, Oxford-Portland, Oregon, Hart Publishing, 2012, p. 149 y referencias en nota 27.

52 Así, por ejemplo, en aquellos casos en los que la sociedad de que se trate se encuentra sometida al Derecho de un Estado tercero, véase la STJUE (Sala 1. ${ }^{a}$ ) de 11 de septiembre de 2014, asunto C-47/12, Kronos International Inc. y Finanzamt Leverkusen (cit. supra nota 21).

53 Art. 50.1 TFUE. Obviamente, lo dicho respecto a las sociedades constituidas según el Derecho de un Estado miembro de la UE ha de extenderse también a las sociedades que han sido creadas de acuerdo con lo previsto en el Derecho de un Estado parte del Acuerdo sobre el Espacio Económico Europeo. Véase el art. 34.1 del Acuerdo sobre el Espacio Económico Europeo, DO L núm. 1, de 3 de enero de 1994.

54 La propuesta del Grupo Europeo de Derecho Internacional Privado ya citada (supra nota 4) se extiende también a sociedades constituidas fuera de la UE (véase art. 2 de la Propuesta). Excluida para estas sociedades la base jurídica que resulta del art. 50.1 TFUE, la actuación de la UE deberá descansar en lo previsto en el art. 81.2.c) TFUE ( «la compatibilidad de las normas aplicables en los Estados miembros en materia de conflictos de leyes y de jurisdicción»), desvinculando la regulación de la garantía del derecho a la libertad de establecimiento (véase sobre el debate entre la base jurídica societaria y conflictual, con anterioridad al TFUE, ZIMmER, D., «Sitzungsbericht vom 23./24. Januar 2004», en SONNENBERger, H. J. (ed.), Vorschläge un Bericthe zur Reform des europäischen un deutschen internationalen Gesellschaftsrechts, Tubinga, Mohr Siebeck, 2007, pp. 201-215, p. 202). Esta base jurídica podría permitir una regulación conflictual del Derecho internacional privado de sociedades que se extendiera a sociedades constituidas en terceros países; pero no sería suficiente para una regulación material, necesaria, por ejemplo, para la transferencia internacional de la sede social. Más allá del problema de la base jurídica, el hecho de ofrecer el mismo tratamiento a las sociedades constituidas en Estados miembros de la UE y en Estados terceros también puede plantear algunos problemas valorativos, véase Sonnenberger, H. J. y Bauer, F. (eds.), «Proposal of the Deutscher Rat für Internationales Privatrecht for European and national legislation in the field of international company law», en SoNNENBERGER, H. J. (ed.), op. cit., pp. 65-122, esp. pp. 78-79. 
societatis ya no será el Derecho de acuerdo con el cual la sociedad se haya constituido el rector de la misma. En estos supuestos tal Derecho será el del Estado al que se haya trasladado la sociedad. Esta circunstancia tendrá que ser tenida en cuenta en la formulación de la norma de conflicto en materia societaria.

22. La determinación de cuál sea la lex societatis en el ámbito europeo de integración no es, sin embargo, más que el primer paso en la regulación conflictual de las sociedades que operan en la UE. Esta determinación es una mera formalidad sin la concreción de las materias que serán regidas por la lex societatis. Partiendo de la asunción de que todas las cuestiones relativas a la vida interna de la sociedad han de regirse por la lex societatis, la concreción de esta es un paso determinante en la configuración de su régimen jurídico; pero actualmente, y más en el ámbito europeo, no hemos de dar por descontada esa asunción, siendo posible que aspectos diversos de la vida social se rijan por Derechos también diferentes. Es por eso por lo que una regulación europea debería especificar las cuestiones que regiría esta lex societatis.

En primer lugar, resultará obligado que la constitución misma de la sociedad se rija por el Derecho del Estado de constitución. Esta tautología no es tal si consideramos que la teoría de la sede había mantenido que el Derecho que debería regir la creación de la sociedad debería ser el del Estado en el que se ubicaba la sede real de la sociedad, incluso aunque no fuera este el Estado de constitución, lo que conducía a la denegación del reconocimiento de la personalidad jurídica de la sociedad ${ }^{55}$. Dado que la libertad de establecimiento exige el reconocimiento de las sociedades constituidas de acuerdo con lo previsto en el Derecho de los Estados miembros de la UE, no es posible más que optar por que la lex societatis sea la del Estado de constitución y rija, entre otras cuestiones, la forma en que es creada la sociedad.

Aparte de la creación de la sociedad y, por tanto, también en buena lógica la validez y nulidad de la misma, la capacidad de la sociedad también debería regirse por la ley del Estado de constitución de la misma ${ }^{56}$; así como su disolución ${ }^{57}$. Esta es una consecuencia, como hemos visto, de la jurisprudencia del Tribunal de Luxemburgo. Podría discutirse hasta dónde llega la exigencia de consideración del Derecho del Estado de constitución de la sociedad en relación a la capacidad de la misma, ya que, por ejemplo, podría entenderse que no vulnera las exigencias de la libertad de establecimiento que la determinación de las personas con capacidad para vincular a la sociedad pueda realizarse según lo previsto en el Derecho donde actúa la sociedad o que la concreción de los casos en los que la sociedad queda vinculada por la actua-

\footnotetext{
55 Véase Arenas García, R., «La lex societatis en el Derecho de las sociedades internacionales», en Derecho de los Negocios, año 7, 1996, núms. 70-71, pp. 11-26, esp. p. 12 y nota 22.

56 Con los matices que han de hacerse para el caso en el que se haya producido la transferencia del domicilio social, tal como se ha indicado.

57 No debería quedar necesariamente incluido en el régimen de la disolución de la sociedad la cuestión de «sociedad residual», problema que ya ha planteado en Alemania, véase KLÖHN, L., «Das Gesellschaftsstatut der Restgesellschaft», IPRax, 2015, núm. 5, pp. 412-417.
} 
ción de sus representantes se haga según un Derecho diferente al del Estado de constitución ${ }^{58}$. Precisamente para cubrir estos supuestos en los que puede resultar dudoso el alcance de la libertad de establecimiento sobre la regulación conflictual podría ser de utilidad una actuación del legislador europeo que estableciera normas claras sobre estos puntos. Una opción posible en estos supuestos sería remitir estas cuestiones también al Derecho del Estado de constitución ${ }^{59}$. De optar por esta solución la norma de conflicto resultante podría tener este tenor:

«Artículo I.a): Las sociedades constituidas de acuerdo con el Derecho de un Estado miembro se regirán por el Derecho de dicho Estado en lo que se refiere al régimen de creación, así como la validez, nulidad y disolución de la misma. También se regirá por este Derecho la capacidad de la sociedad, incluyendo la representación orgánica de la sociedad y los supuestos en los que la sociedad quedará vinculada por la actuación de sus representantes legales».

23. El régimen de la responsabilidad de los administradores debería ser también objeto de atención por parte del legislador europeo; teniendo en cuenta que ahora mismo algunos supuestos de responsabilidad ya están regulados en el Derecho derivado. En concreto, aquellos que se enmarcan en un procedimiento de insolvencia, resultando entonces aplicable el Reglamento $1346 / 2000^{60}$. Fuera de los casos de insolvencia, sin embargo, no existe actualmente regulación conflictual en relación a este tema en el Derecho derivado, pues las cuestiones relativas a responsabilidad de los administradores se encuentran excluidas del ámbito de aplicación de los Reglamentos Roma I ${ }^{61}$ y Roma II ${ }^{62}$.

58 Véase Arenas García, R., «Lex societatis y derecho... », op. cit., nota 3, p. 161.

59 La propuesta del GEDIP (supra nota 4) incluye una regla sobre la excepción del interés nacional (art. 6) que permitiría la entrada del Derecho del lugar de celebración del contrato. Es cierto que, probablemente, esta limitación en la aplicación del Derecho del Estado de constitución en materia de capacidad no es incompatible con la libertad de establecimiento, tal como acabamos de ver (véase supra nota anterior); pero la remisión al Derecho del Estado de constitución evitaría las dudas sobre la compatibilidad con el Derecho originario que pudieran derivarse de la consideración de un Derecho diferente. Hemos de tener en cuenta que pese a que es difícil la declaración de que una norma de Derecho secundario es contraria al Derecho europeo originario (véase TEICHMANN, Ch., "Gesellschaftsrecht im System der Europäischen Niederlassunsfreiheit», ZGR, 2011, pp. 639-689, esp. p. 657; lo cierto es que el legislador europeo está vinculado por las exigencias derivadas de las libertades fundamentales (ibid., pp. 655-658), aunque probablemente el margen de actuación de este legislador europeo es mayor que el de los legisladores nacionales (ibid., p. 658; ArEnAS GARcía, R., "Lex societatis y derecho...», op. cit., p. 160). Por otra parte, la introducción de una norma en materia de la excepción del interés nacional en relación a la capacidad de las sociedades es probablemente menos necesaria que respecto a las personas físicas (téngase en cuenta que en el Reglamento Roma I se ha optado conscientemente por limitar esta excepción a las personas físicas), en especial si existe una regulación europea sobre la materia.

60 Reglamento (CE) núm. 1346/2000, del Consejo, de 29 de mayo, sobre procedimientos de insolvencia (DO L núm. 160, de 30 de junio de 2000), sustituido a partir del 26 de junio de 2017 por el Reglamento (UE) 2015/848, del Parlamento Europeo y del Consejo, de 20 de mayo, sobre procedimientos de insolvencia, DO L núm. 141, de 5 de junio de 2015.

61 Reglamento (CE) núm. 593/2008, del Parlamento Europeo y del Consejo, de 17 de junio, sobre la ley aplicable a las obligaciones contractuales (Roma I), DO L núm. 177, de 4 de julio de 2008.

62 Reglamento (CE) núm. 864/2007, del Parlamento Europeo y del Consejo, de 11 de julio, relativo a la ley aplicable a las obligaciones extracontractuales (Roma II), DO L núm. 199, de 31 de julio de 2007. 
La ausencia de regulación actual - excepto en los casos de responsabilidad vinculada casos de insolvencia empresarial — debería ser suplida por una actuación del legislador europeo que tuviera en cuenta los condicionantes derivados del Derecho originario. Como hemos visto, el Tribunal de Luxemburgo ha mostrado que el régimen de responsabilidad de los administradores no es indiferente a las exigencias de la libertad de establecimiento; aunque sin llegar al punto de exigir que indefectiblemente esta responsabilidad haya de regirse por el Derecho del Estado de constitución, tal como hemos examinado en el epígrafe 2 de este trabajo. La necesaria toma en consideración de dicho Derecho abre suficientes interrogantes como para aconsejar la actuación del legislador europeo. Una actuación que permitiría ofrecer un régimen común al tratamiento conflictual de esta responsabilidad que aportaría uniformidad y seguridad jurídica.

La opción que mejor respondería a estas exigencias (las derivadas de la libertad de establecimiento y la seguridad jurídica) a la vez que proporcionaría una mayor simplicidad sería aquella que remitiera la regulación de la responsabilidad de los administradores al Derecho del Estado de constitución de la sociedad. De esta forma, se daría pleno cumplimiento a las exigencias derivadas del Derecho originario europeo y, a la vez, se ofrecería una solución única que responde a una conexión estrecha entre el Derecho designado y la materia de la que se ocupa, pues no cabe duda de que la ley del Estado de constitución de la sociedad presenta un vínculo más que suficiente para regir la responsabilidad de los administradores sociales. Ahora bien, esta remisión al Derecho del Estado de constitución aún tiene que ser objeto de dos matices.

24. En primer lugar, sería necesario diferenciar entre la responsabilidad del administrador de carácter societario, la de naturaleza extracontractual ${ }^{63}$ y, en segundo término, considerar las especificidades de la responsabilidad en supuestos de insolvencia. En lo que se refiere a esta última cuestión, debe respetarse el ámbito de aplicación del Reglamento 1346/2000, tal como ya se ha adelantado, lo que implicará que en aquellos casos en los que la responsabilidad del administrador esté conectada con un procedimiento de insolvencia será el Reglamento de Insolvencia el que deberá aplicarse. De esta forma, debería trasladarse a la determinación del Derecho aplicable los criterios de diferenciación entre el Reglamento 1346/2000 y el Reglamento Bruselas I que

63 Véanse Arenas García, R., «La responsabilidad de los administradores sociales desde la perspectiva del Derecho internacional privado», en Arenas García, R., GórRiz LóPEz, C. y Miquel García, J. (coords.), La internacionalización del Derecho de sociedades, op. cit., nota 9, pp. 157-200, esp. pp. 189190; id., "Suing directors in International litigation", en GRUNDMANN, S. et al. (dirs.), Festscrhrift für Klaus J. Hopt zum 70. Geburtstag am 24. August 2010. Unternehmen, Markt und Verantwortung, BerlínNueva York, Walter de Gruyter, t. I, 2010, pp. 321-335, esp. pp. 322-325; ZHANG, H., Directors' Liability from the Perspective of Private International Law, tesis, UAB, 2014, pp. 9-58. Esta distinción ha sido considerada por el GEDIP en su tratamiento de la responsabilidad de los administradores en el marco de una normativa sobre Derecho internacional privado de sociedades, véase el informe sobre las sesiones de trabajo del grupo en su reunión de Luxemburgo del año 2015 (http://www.gedip-egpil.eu/ reunionstravail/gedip-reunions-25.htm, consultado el 24 de noviembre de 2016). 
ha ido manteniendo la jurisprudencia del Tribunal de Luxemburgo ${ }^{64}$. Se trata de evitar solapamientos entre instrumentos de tal forma que en aquellos casos que entren en el ámbito de aplicación del Reglamento de insolvencia no tendrían aplicación otros; siendo deseable que no se produjeran tampoco lagunas de regulación ${ }^{65}$. De esta forma, la regulación que se hiciera de la responsabilidad de los administradores debería excluir aquellos supuestos que entran en el ámbito de aplicación del Reglamento de insolvencia.

Resulta más problemática la diferenciación entre los aspectos societarios y meramente extracontractuales en la responsabilidad de los administradores $^{66}$. En ocasiones no resultará sencillo separar ambas dimensiones y, probablemente, sería oportuna una interpretación amplia de la remisión a la lex societatis en materia de responsabilidad de los administradores que cubriera no solamente la responsabilidad derivada del incumplimiento de las obligaciones que se derivarían de las obligaciones societarias de los administradores, sino también la determinación de los casos en los que el administrador responderá personalmente de las obligaciones societarias ${ }^{67}$. Cuestión distinta es la responsabilidad directa del administrador por sus actuaciones. En caso

${ }^{64}$ Véanse AREnAS GARcía, R., «La responsabilidad de los administradores...», op. cit., nota 63, p. 169; id., «Suing directors...», op. cit., nota 63, pp. 331-334; ZHANG, H., op. cit., nota 63, pp. 131-152.

${ }_{65}$ Actualmente esta idea se encuentra plasmada en el cdo. 7 del Reglamento 2015/848: «La quiebra, los convenios entre quebrado y acreedores y demás procedimientos análogos, así como las acciones relacionadas con esos procedimientos, están excluidos del ámbito de aplicación del Reglamento (UE) núm. 1215/2012, del Parlamento Europeo y del Consejo. Dichos procedimientos deben quedar sujetos al presente Reglamento. En la mayor medida posible, la interpretación del presente Reglamento debe evitar resquicios normativos entre ambos instrumentos. Sin embargo, el mero hecho de que un procedimiento nacional no figure en la lista del anexo A del presente Reglamento no ha de significar que esté sujeto al Reglamento (UE) núm. 1215/2012».

${ }^{66}$ En la propuesta del GEDIP se opta por remitir la solución de los problemas que de aquí se derivan a un considerando del instrumento que hipotéticamente incorporaría la regulación que se ofrece. Véanse nota 1 y 2 de la propuesta del GEDIP, véase supra nota 4 . A la vez se excluye del ámbito de aplicación del instrumento propuesto la responsabilidad de los administradores frente a terceros [art. 1.2.a) de la Propuesta]. Se trata de una solución discutible, porque dejaría fuera de la regulación una cuestión que sí ha sido ya considerada por la jurisprudencia del Tribunal de Luxemburgo: la responsabilidad de los administradores sociales frente a terceros por incumplimiento de las obligaciones de publicidad de la sociedad (Sentencia Inspire Art, véase supra apdo. 6). En este caso se propone, por parte del GEDIP, la aplicación del Reglamento Roma II; pero esto obligaría a una modificación del ámbito de aplicación de este instrumento (véase infra nota siguiente). Para una propuesta que remite a la lex societatis la responsabilidad de los administradores tanto frente a la sociedad y socios como frente a terceros (siempre que deba ser calificada como societaria), véase SoNNENBERGER, H. J., op. cit., nota 54 , p. 100.

${ }^{67}$ Una cuestión que, por ejemplo, se encuentra expresamente excluida del ámbito de aplicación del Reglamento Roma II, véase el art. 1.2.d) del Reglamento, que excluye del ámbito de aplicación del Reglamento «las obligaciones extracontractuales que se deriven del Derecho de sociedades, asociaciones y otras personas jurídicas, relativas a cuestiones como la constitución, mediante registro o de otro modo, la capacidad jurídica, el funcionamiento interno y la disolución de sociedades, asociaciones y otras personas jurídicas, de la responsabilidad personal de los socios y de los administradores como tales con respecto a las obligaciones de la sociedad u otras personas jurídica y de la responsabilidad personal de los auditores frente a una sociedad o sus socios en el control legal de los documentos contables». Esta exclusión impide que sean los Reglamentos Roma II, si se trata de responsabilidad extracontractual, o Roma I, para los supuestos de responsabilidad contractual, los que determinen la responsabilidad personal del administrador por las obligaciones de la sociedad. 
de que de estas pueda derivarse una responsabilidad para este de carácter extracontractual debería ser aplicable la norma de conflicto en materia extracontractual, que sería la que determinaría tal responsabilidad.

Teniendo lo anterior en cuenta resultaría que la norma de conflicto que podría formularse en materia de responsabilidad de los administradores podría ser la siguiente:

«Artículo II: La responsabilidad de los administradores sociales en su calidad de tales, tanto frente a la sociedad y los socios como frente a los terceros, incluyendo también la determinación de los casos en los que los administradores deberán responder de las deudas sociales por su condición de administradores vendrá determinada por la ley del Estado de constitución de la sociedad.

En los casos en los que la responsabilidad de los administradores traiga su causa de una situación de insolvencia regida por el Reglamento 1346/2000 será aplicable dicho Reglamento para la determinación del régimen de la responsabilidad del administrador».

25. Tal como hemos visto, el Derecho europeo originario exige que los Estados miembros permitan la conversión de las sociedades regidas por su Derecho en sociedades sometidas al Derecho de otro Estado miembro, siempre que el ordenamiento del Estado de destino permita tal transformación ${ }^{68}$. Aquí no podemos abordar cuál podría ser el régimen de dicho traslado, que exigiría la coordinación entre los Derechos de los Estados de origen y de destino de la sociedad, así como los respectivos registros de sociedades, en línea con los mecanismos que ya existen en relación al traslado de domicilio de una $\mathrm{SE}^{69}$; pero sí que es preciso considerar en qué forma afectará ese cambio de domicilio a la determinación de la lex societatis.

Lo lógico es que en los supuestos de traslado de sede con cambio de la ley rectora de la sociedad la nueva ley opere a partir del cambio pasando a desempeñar el papel que tenía la ley del Estado de constitución de la sociedad. Esta es una aclaración que debería introducirse en la regulación conflictual societaria. El precepto resultante podría ser del siguiente tenor:

«Artículo III: En los supuestos de cambio de domicilio social que supongan la transformación de la sociedad en una forma prevista en el Derecho del Estado al que se traslada el domicilio, y con independencia de las reglas relativas a la operación de traslado, el Derecho del Estado de constitución dejará de regir a la sociedad a partir del momento en el que el traslado sea efectivo. A partir de ese momento será el Derecho del Estado del nuevo domicilio de la sociedad quien rija la capacidad de la sociedad y la responsabilidad de los administradores sociales».

68 Sentencias Cartesio y VALE ya examinadas (supra párr. 13). Tal como se vio en su momento, el Derecho del Estado de destino de la sociedad no tiene una facultad libérrima para regular la inmigración de sociedades.

${ }_{69}$ Véase el art. 8 del Reglamento de la SE (véase supra nota 6). Véase, sobre el procedimiento desde la perspectiva del Derecho internacional privado español, Palao Moreno, G., El traslado del domicilio social de la Sociedad Anónima Europea, Cizur Menor, Thomson-Aranzadi, esp. pp. 141-196. 
26. La introducción de las normas que han sido propuestas en los párrafos anteriores permitiría dotar de seguridad jurídica al tráfico intracomunitario, evitando las dudas que ahora se derivan de la interpretación de la jurisprudencia del Tribunal de Luxemburgo y la articulación de esta con los Derechos de origen interno de los Estados miembros. Aquí se han considerado tan solo aquellas cuestiones que hasta ahora han sido objeto de atención por la jurisprudencia del Tribunal de Luxemburgo, pero en caso de que el legislador europeo optara por abordar el tratamiento del DIPr de sociedades en el ámbito intraeuropeo podría extenderse la aplicación de la ley del Estado de constitución de la sociedad también al régimen interno de esta, con lo que no se haría más que dotar de carta de naturaleza a la práctica existente, que en buena medida se da por supuesta incluso en la regulación derivada europea relativa al régimen interno de las sociedades ${ }^{70}$, pese a que ninguna norma ni de Derecho originario ni derivado recoge esa regla. La introducción de una normativa europea en materia de DIPr de sociedades sería la ocasión para explicitar este principio, lo que implicaría que el art. I que se proponía un poco más arriba debería incluir entre las cuestiones regidas por el Derecho del Estado de constitución de la sociedad todas las cuestiones relativas al funcionamiento interno de la sociedad.

«Artículo I.b): Las sociedades constituidas de acuerdo con el Derecho de un Estado miembro se regirán por el Derecho de dicho Estado en lo que se refiere al régimen de creación, así como la validez, nulidad y disolución de la misma. También se regirá por este Derecho la capacidad de la sociedad, incluyendo la representación orgánica de la sociedad y los supuestos en los que la sociedad quedará vinculada por la actuación de sus representantes legales. Este mismo Derecho regirá el funcionamiento interno de la sociedad».

${ }^{70}$ Los distintos instrumentos existentes asumen que es el Derecho del Estado de acuerdo con el cual se ha creado la sociedad el que rige el funcionamiento de esta. Véase, por ejemplo, el art. 1 de la Directiva 2013/34/UE, del Parlamento Europeo y del Consejo, de 26 de junio, sobre los estados financieros anuales, los estados financieros consolidados y otros informes afines de ciertos tipos de empresas, por la que se modifica la Directiva 200/46/CE, del Parlamento Europeo y el Consejo, y se derogan las Directivas 78/660/CEE y 83/349/CEE del Consejo (DO L núm. 182, de 29 de junio de 2013). En este art. 1 se indica que las medidas prescritas por la Directiva se aplicarán a las disposiciones legales, reglamentarias y administrativas de los Estados miembros relativas a las formas de sociedades que figuran en el Anexo I de la Directiva. A su vez, en dicho Anexo I se indica país por país que formas societarias son estas (en el caso de España, por ejemplo, se trata de la sociedad anónima, la sociedad comanditaria por acciones y la sociedad de responsabilidad limitada). Para que las prescripciones de la Directiva tengan pleno sentido hemos de asumir que a las sociedades españolas (por ejemplo) designadas en el Anexo I de la Directiva se les aplicarán las normas españolas que transponen la Directiva. Eso será así evidentemente en los supuestos puramente internos; pero parece razonable extender esta solución a los supuestos que presentan conexiones con más de un ordenamiento. Cualquier otra interpretación resultaría, al menos, alambicada. En esta misma línea interpretativa parece descansar la jurisprudencia del Tribunal de Luxemburgo cuando mantiene, por ejemplo, que resulta legítimo que los fundadores de una sociedad constituyan una sociedad en el Estado cuyas normas de Derecho de sociedades prefieran (así, por ejemplo, en la Sentencia Centros ya mencionada, véase supra nota 2, apdo. 27 de la sentencia). Merece, sin embargo, un tratamiento específico la Directiva sobre OPAS (Directiva 2004/25/CE, del Parlamento Europeo y del Consejo, de 21 de abril, relativa a las ofertas públicas de adquisición, DO L núm. 142, de 30 de abril de 2004) ya que en esta la falta de concreción del Estado miembro competente plantea la duda de si tal competencia ha de atribuirse al Estado de constitución de la sociedad o al de mercado en el que cotiza, véase BenedetTelli, M. V., op. cit., nota 5, pp. 229-230. 
27. De acuerdo con lo anterior, por tanto, bastarían unos pocos preceptos para ofrecer un régimen del DIPr de sociedades en la UE que permitiera traducir en Derecho positivo la jurisprudencia del Tribunal de Luxemburgo sobre la proyección de las exigencias de la libertad de establecimiento sobre la regulación de la actividad internacional de las sociedades, a la vez que facilitaría un régimen conflictual único para todos los Estados europeos. Dada la importancia que tienen en la actualidad las sociedades constituidas de acuerdo con el Derecho de origen interno de los Estados miembros para el ejercicio de la libertad de establecimiento dentro de la UE una regulación como la propuesta supondría una facilitación significativa de la libre circulación de personas jurídicas en Europa.

Sería deseable que se superaran las reticencias que el legislador europeo ha mostrado hasta ahora y que finalmente se avanzara hacia la formulación de estas normas europeas en materia de DIPr societario.

\section{CONCLUSIÓN}

28. El régimen de la actividad internacional de las sociedades en la UE está condicionado por las exigencias de la libertad de establecimiento. Estas exigencias, que han tenido reflejo en la jurisprudencia del Tribunal de Luxemburgo no han sido trasladadas a normas de Derecho derivado. La reticencia del legislador europeo en abordar estas cuestiones es clara, pero no se encuentra justificada. En las circunstancias actuales favorecería la seguridad jurídica y la integración económica la existencia de algunas reglas claras sobre DIPr de sociedades en Europa.

La promulgación de una serie de reglas que formalizaran el principio de acuerdo al cual las sociedades constituidas según el Derecho de un Estado miembro han de regirse por el Derecho de dicho Estado, al menos en lo que se refiere a las cuestiones de capacidad y de responsabilidad de los administradores, sería aconsejable. Sería recomendable una regulación más amplia que previera que las sociedades beneficiarias de la libertad de establecimiento deberían regirse por el Derecho del Estado de constitución excepto en los casos en los que se hubiera producido la transferencia del domicilio social a otro Estado miembro y la transformación de la sociedad en una regida por el Derecho de dicho Estado. Esta regulación debería completarse precisamente con la específica para las operaciones de transferencia internacional de la sede social.

\section{RESUMEN}

\section{EL LEGISLADOR EUROPEO Y EL DIPR DE SOCIEDADES EN LA UE}

La jurisprudencia del Tribunal de Luxemburgo ha mostrado que la libertad de establecimiento que recoge el Derecho de la UE condiciona no solamente el Derecho sustancial de sociedades de los Estados miembros, sino también las reglas sobre conflicto de leyes en materia societaria. 
Ante la inexistencia de normas de Derecho derivado en materia de determinación del Derecho aplicable a las sociedades en la UE y con el fin de mejorar la seguridad jurídica sería conveniente que el legislador europeo elaborase normas que regulasen la determinación de la lex societatis de las sociedades constituidas en Estados miembros de la UE, la concreción de las materias que regularía esta lex societatis y el cambio de lex societatis como consecuencia de la transferencia del domicilio social. Entre las materias reguladas debería incluirse necesariamente la capacidad de la sociedad y la responsabilidad de los administradores sociales, delimitando en este punto el alcance de la regulación específicamente societaria y de la relativa a procedimientos de insolvencia.

Palabras clave: Derecho de sociedades, UE, libertad de establecimiento, capacidad de las personas jurídicas, responsabilidad de los administradores sociales, transferencia internacional del domicilio social.

\section{ABSTRACT \\ THE EUROPEAN LEGISLATOR AND THE PRIVATE INTERNATIONAL LAW OF COMPANIES IN THE EU}

Luxemburg Court's case law has shown that the freedom of establishment granted by the EU law affects not only the substantive company law of the Member States, but also the conflict of laws rules in matters relating to companies.

In the absence of secondary legislation relating to the law governing companies in the EU, and in order to improve legal certainty it would be desirable that the European legislator draw up rules aimed to determine which will be the lex societatis governing companies incorporated in EU countries. This regulation should also concretize the matters ruled by this lex societatis and the change of the lex societatis as a result of the transfer of the registered office of the company. Among the subjects covered by this regulation it should necessarily be included the company's legal capacity and the directors' liability. It would be also necessary to delimitate the scope of the specific corporate regulation and that relating with insolvency proceedings.

Keywords: company law, European Union, freedom of establishment, capacity of legal persons, directors' liability, cross-border transfer of companies. 